\title{
ОРГАНИЗАЦИЯ ТАМОЖЕННОГО КОНТРОЛЯ ТОВАРОВ, ПЕРЕМЕЩАЕМЫХ В РАMKAX SMART-КOHTPAKTOB: ПРИНЦИПЫ И ФАКТОРЫ ПОВЫШЕНИЯ ЭФФЕКТИВНОСТИ
}

\section{ORGANIZATION OF CUSTOMS CONTROL OF GOODS MOVED UNDER SMART CONTRACTS: PRINCIPLES AND FACTORS TO INCREASE EFFICIENCY}

V. Polyakova

Summary. Currently, innovative methods and technologies for registration of foreign trade transactions for the purchase and sale of goods are being intensively developed. One of such innovative technologies for registration of foreign trade transactions is a smart contract. The article presents the definition of the term "smart contracts", highlights the basic principles of customs control of goods transported within the framework of smart contracts. In addition, the article proposes the main factors that provide an increase in the efficiency of customs control of goods transported under smart contracts, as well as methods of obtaining them and methods of assessment.

Keywords: foreign trade transactions, smart contracts, blockchain, blockchain technologies, customs control, principles of customs control.

\author{
Полякова Владислава Маратовна \\ Аспирант, Российская таможенная академия \\ vladissyneo@yandex.ru
}

Аннотация. В настоящее время интенсивно развиваются инновационные методы и технологии оформления внешнеторговых сделок купли-продажи товаров. Одной из таких инновационных технологий оформления внешнеторговых сделок является smart-контракт. В статье представлено определение термина «smart-контракты», выделены основные принципы таможенного контроля товаров, перемещаемых в рамках smart-контрактов. Кроме того, в статье предложены основные факторы, которые обеспечивают повышение эффективности таможенного контроля товаров, перемещаемых в рамках smart-контрактов, а также методов их получения и способов оценки.

Ключевые слова: внешнеторговые сделки, smart-контракты, blockchain, blockchain-технологии, таможенный контроль, принципы таможенного контроля. сли подойти к рассмотрению сущности smart-контрактов, то следует согласиться с А.С. Осмоловской, которая писала, что под smart-контрактами следует понимать алгоритм математического характера, ориентированный на автоматизацию контрактов между контрагентами. Также в собственном научном исследовании ученый подчеркивает, что такого рода контракты являются набором действий и правил последовательного характера. Правила исполнения действий последовательного характера выступают условиями smart-контракта, они проверяются алгоритмом автоматически, а потом по цифровому протоколу осуществляется исполнение условий [3]. Опираясь на такое определение можно заключить, что smart-контракты предполагают автоматизацию всего процесса заключения контракта.

В статье Н.А. Усольцевой, Ю.М. Усольцева и Д.С.Дядькина подчеркивается, что smart-контракт не считается с позиции договорного права отдельной разновидностью договора или видом обязательства, в результате чего следует его рассматривать как способ обеспечения исполнения обязательств договорно- го характера или форму соответствующего договора [2].

В свою очередь, в работе Д.А. Позднякова и М.Ю. Юрасова отмечается, что smart-контракты выступают «умными контрактами», которые в систему современного договорного права могут быть интегрированы с помощью двух моделей интеграции:

- гибридная интеграционная модель, представляющая собой самостоятельный элемент договора, включающий условия, которые в тексте на бумажном носителе не прописаны;

- обособленная интеграционная модель, т.е. дополнительный элемент привычного договора, который заключается в письменной форме [4].

Опираясь на исследования ученых, можно заключить, что в настоящее время пока не достижим полный уход от традиционной письменной формы заключения контрактов к smart-контрактам. Мы полагаем, что данный факт, прежде всего, обусловлен тем, что в основе функционирования большинства smart-контрактов лежит технология blockchain, регулирование которой, как 


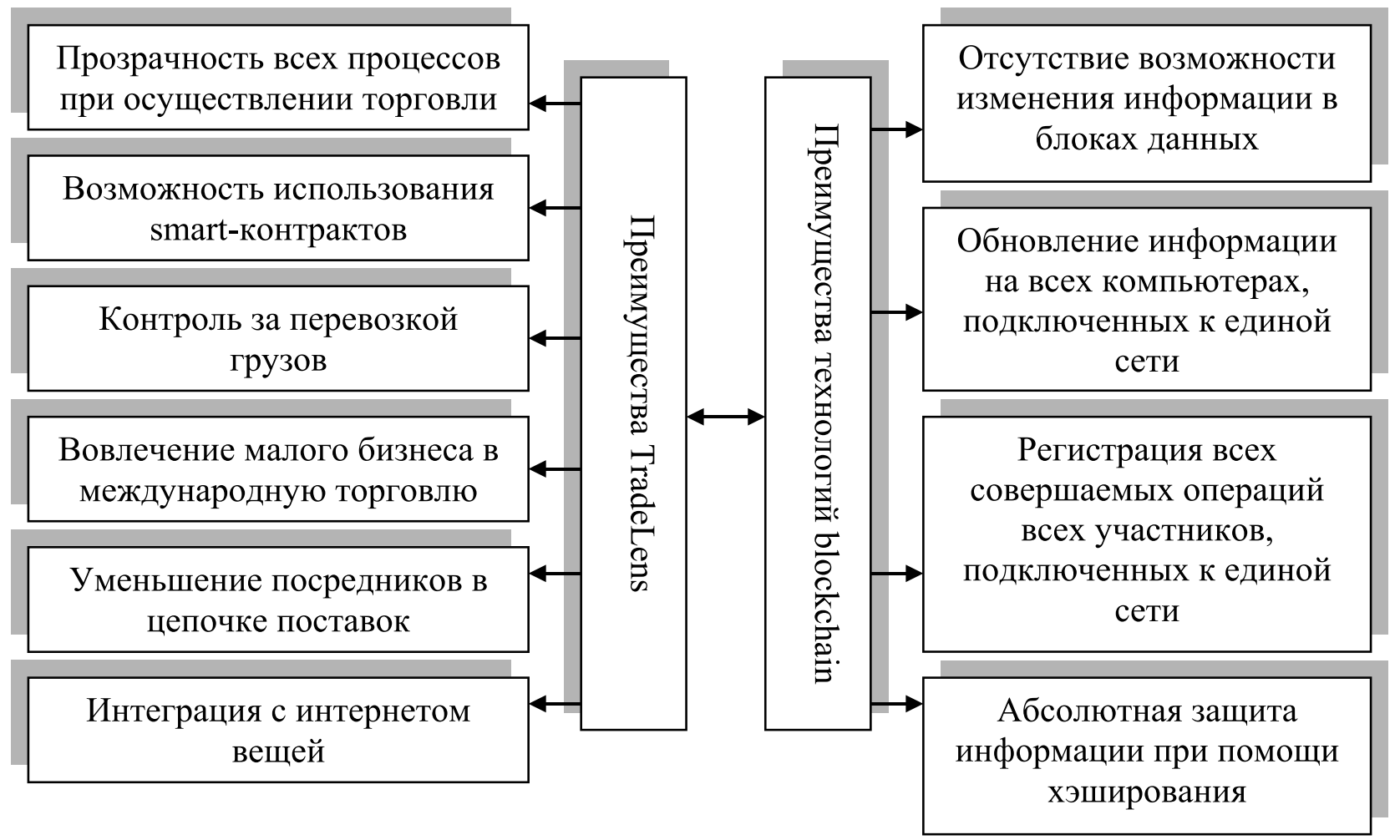

Рис. 1. Основные преимущества платформы TradeLens

и, собственно, регулирование заключения smart-контрактов отсутствует.

На пути к «автономии» smart-контрактов значительным препятствием считается невозможность вмешательства в программный код в результате использования системы blockchain. В этом контексте все же стоит подчеркнуть, что такая проблема может быть и преимуществом, если использовать такую систему в иных правовых отраслях.

Если опираться на зарубежный опыт в сфере таможенного контроля, то blockchain-технологии могут быть использованы для управления товарной номенклатурой и в сфере осуществления контроля страны происхождения товаров, и в сфере верификации сертификатов такого происхождения.

Основным преимуществам и возможностям использования технологий blockchain также уделяется внимания и со стороны российских государственных органов. В научных исследованиях А.И. Бубеля описаны основные возможности использования в деятельности органов таможенного регулирования технологий распределенного реестра. Учебный выделяет следующие возможности:

- электронный документооборот;

- регистрация участников ВЭД; ф формирование книги учета таможенных деклараций;

- расчет суммы таможенных платежей (автоматический) и так далее [1].

Одной из перспектив использования blockchain-технологий при таможенном контроле товаров, перемещаемых в рамках smart-контрактов, считается возможность органов таможенного регулирования осуществлять автоматический выпуск деклараций на товары (рис. 1).

Следующим преимуществом использования блокчейн-технологий при таможенном контроле товаров, перемещаемых в рамках smart-контрактов, считаются возможности анализа цепи поставок с целью совершенствования системы управления рисками. Для органов таможенного регулирования требуется сформировать базу данных, имеющую связь с Q-R-кодами роскошных товаров. Так, фирма Everledger специализируется на сертификации бриллиантов. Каждый товар, который относится к предмету роскоши, на соответствующей blockchain-платформе в данном случае будет иметь «аналог паспорта», которому должны доверять органы таможенного регулирования.

Опираясь на исследования ученых, можно заключить, что в настоящее время пока не достижим полный 


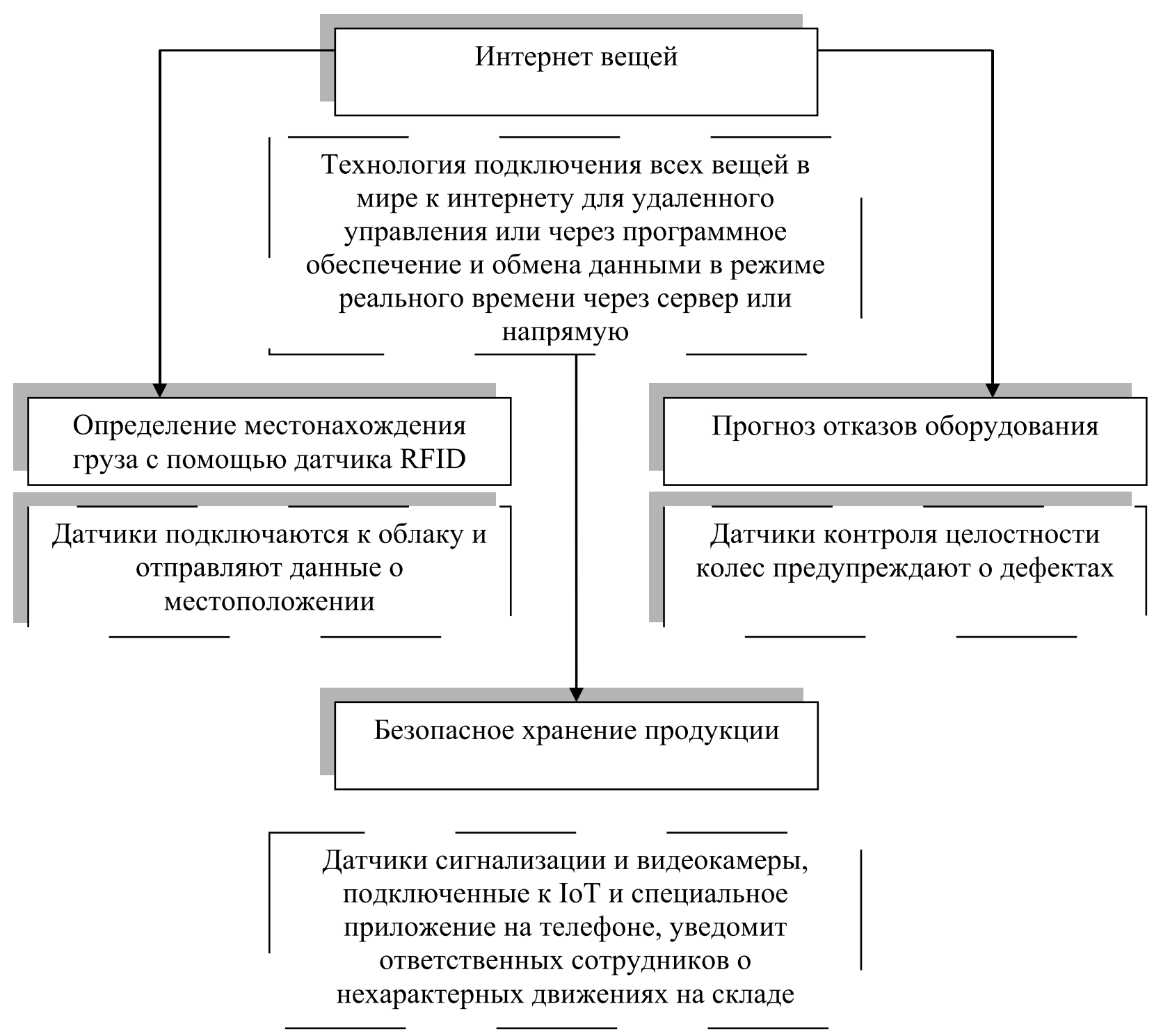

Рис. 2. Основные возможности использования системы blockchain в интеграции с технологиями интернета вещей в отношении участников внешнеэкономической деятельности

уход от традиционной письменной формы заключения контрактов к smart-контрактам. Мы полагаем, что данный факт, прежде всего, обусловлен тем, что в основе функционирования большинства smart-контрактов лежит технология blockchain, регулирование которой, как и, собственно, регулирование заключения smart-контрактов отсутствует.

Постановлением Правительства РФ от 4 июня 2019 г. № П9-30491 было положено начало внедрения технологий blockchain в систему таможенных органов, а также их внедрение и развитие обусловлено Меморандумом о взаимодействии по запуску пилотного проекта по внедрению платформы блокчейн TradeLens между A.P. Moller-Maersk, ФГУП «Морсвязьспутник» и Мини- стерства транспорта России. Основные преимущества TradeLens схематически представлены на рисунке 1.

Благодаря технологии blockchain можно защищать на максимальном уровне данные, вносимые в базу, что важно для участников внешнеэкономической деятельности и для ГКО. В свою очередь, для органов таможенного регулирования это необходимо для обеспечения в РФ информационной безопасности.

Использование платформы blockchain TradeLens в организации таможенного контроля товаров, перемещаемых в рамках smart-контрактов, предполагает интеграция с технологией интернета вещей, что обусловливает так же необходимость рассмотрения пер- 


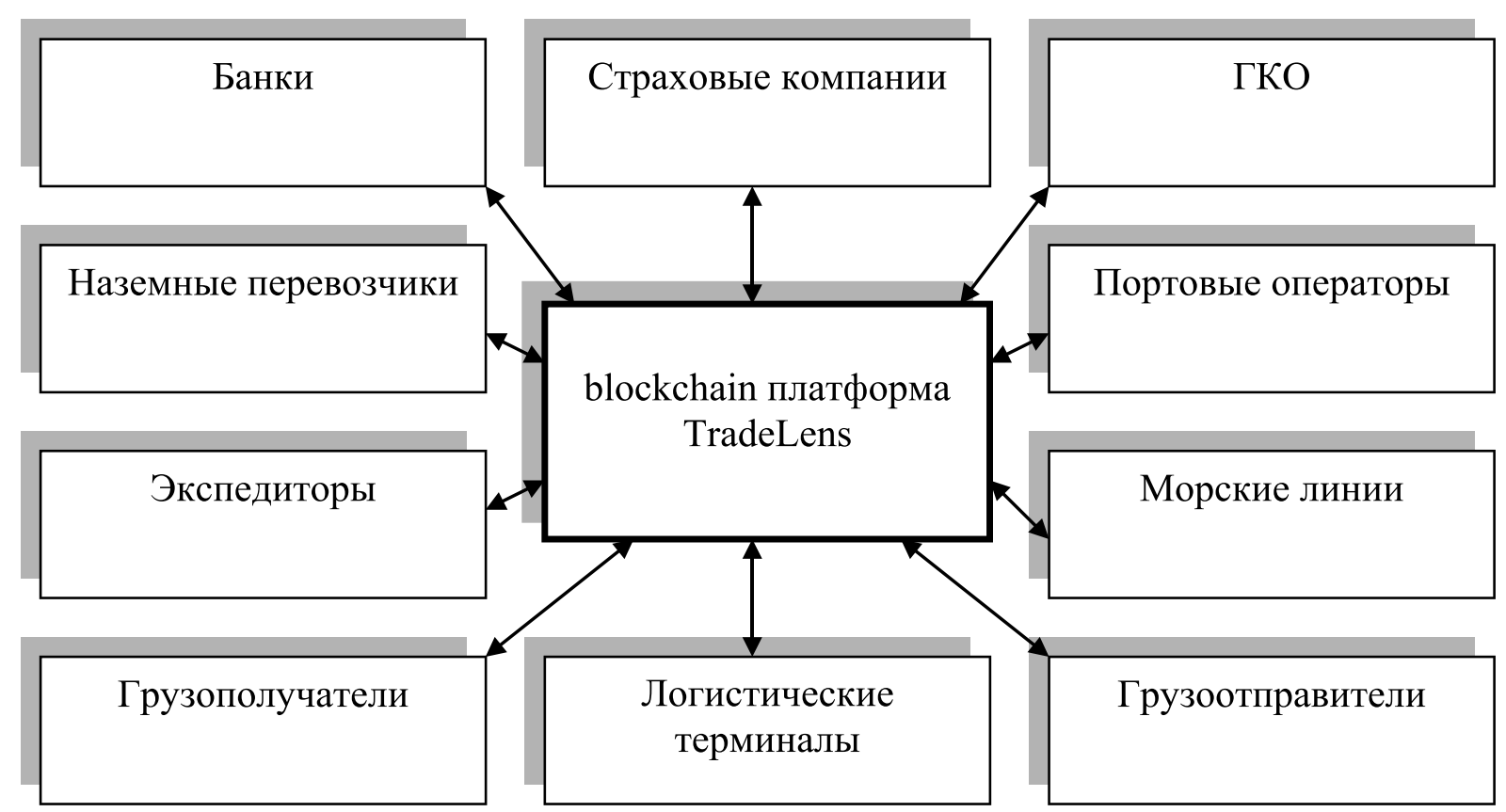

Рис. 3. Основные участники, использующие blockchain платформу TradeLens для перемещения в рамках smart-контрактов и их таможенного контроля

спектив ее использования для участников ГКО И ВЭД. На рисунке 2 схематически представлены основные возможности использования анализируемой системы.

Таким образом, внедрение платформы blockchain и технологии интернета вещей будет, прежде всего, способствовать реорганизации пунктов пропуска товаров в интеллектуальные пункты пропуска товаров, что так же выделено в качестве одного из планов в Стратегии развития таможенной службы до 2030 года. Кроме того, как свидетельствуют данные представленного выше рисунка, благодаря использованию интернет вещей участники ВЭД смогут минимизировать ситуации, в рамках которых может быть сформирован негативный эффект на перемещаемые в рамках smart-контрактов товары, ликвидировать возможности совершения в отношении таких товаров преступных деяний.

Следующим преимуществом использования блокчейн-технологий в сфере таможенного регулирования товаров, перемещаемых в рамках смарт-контрактов, считается передача информационных сведений ФТС о цепи поставок участника ВЭД в рамках технологий blockchain органам контроля. Так, возможна передача таких сведений для ФНС в целях осуществления налогового контроля.

Благодаря использованию платформы blockchain технологий (в частности, платформы TradeLens) обеспечивается электронное и информационное взаимодей- ствие участников совершения таможенных операций по таможенному контролю в отношении товаров, перемещаемых в рамках smart-контрактов.

Схематически основные участники, которые используют blockchain платформу TradeLens для перемещения в рамках smart-контрактов и их таможенного контроля, могут быть представлены следующим образом (рисунок 3).

Выделенные преимущества использования blockchain-технологий при таможенном контроле товаров, перемещаемых в рамках smart-контрактов, должны руководствоваться определенными принципами:

- законность;

- организационная целостность;

- материальная заинтересованность;

- эффективное использование технологий;

- эффективное кадровое управление;

- системный подход.

Использование blockchain-технологий при таможенном контроле товаров, перемещаемых в рамках smart-контрактов, как уже отмечалось ранее в исследовании, может привести к совершенствованию и повышению эффективности таможенного контроля товаров, а также к коренным изменениям в международной торговле [5].

Основными факторами, которые обеспечивают эффективность таможенного контроля товаров, перемещаемых в рамках smart-контрактов, являются: 
- повышение управляемости данными в рамках осуществления таможенного контроля;

- интегрирование органов таможенного регулирования в торговый процесс;

- повышение качества и безопасности товаров, перемещаемых в рамках smart-контрактов;

- улучшение борьбы с финансовыми преступлениями в области таможенного контроля.

Исходя из проведенного исследования, можно прийти к выводу о том, что в сфере таможенного контроля товаров, перемещаемых в рамках smart-контрактов, является достаточно перспективным направлением внедрение blockchain-технологий. Именно поэтому со стороны органом таможенного регулирования требуется проведение более глубокой оценки использования таких технологий, опираясь на основные принципы таможенного контроля товаров, перемещаемых в рамках smart-контрактов, выделенные в статье. В то же время, для повышения эффективности таможенного контроля товаров, перемещаемых в рамках smart-контрактов, требуется учитывать выделенные в статье факторы.

\section{ЛИТЕРАТУРА}

1. Бубель А.И. Возможности использования блокчейна и виртуальных токенов в таможенных операциях // Таможенная политика России на Дальнем Востоке. 2016. № 3. С. 14-22.

2. Дядькин Д.С., Усольцев Ю.М., Усольцева Н.А. Смарт-контракты в России: перспективы законодательного регулирования // Universum: экономика и юриспруденция. - 2018. - № 5 (50).- - С. 17-20.

3. Осмоловская А.С. Смарт-контракты: функции и применение // Бизнес-образование в экономике знаний. — 2018. — № 2 (10). - C. $54-56$.

4. Юрасов М.Ю., Поздняков Д.А. Смарт-контракт и перспективы его правового регулирования в эпоху технологии блокчейн. 2017. URL: https://zakon.ru/ blog/2017/10/9/smart-kontrakt_i_perspektivy_ego_pravovogo_regulirovaniya_v_epohu_tehnologii_blokchejn

5. Antonovici, A. Japan, Singapore Start Blockchain Pilot to Improve Trade Links. 2017. Cryptovest website: https://cryptovest.com/news/japan-singaporestartblockchain-pilot-to-improve-trade-links/

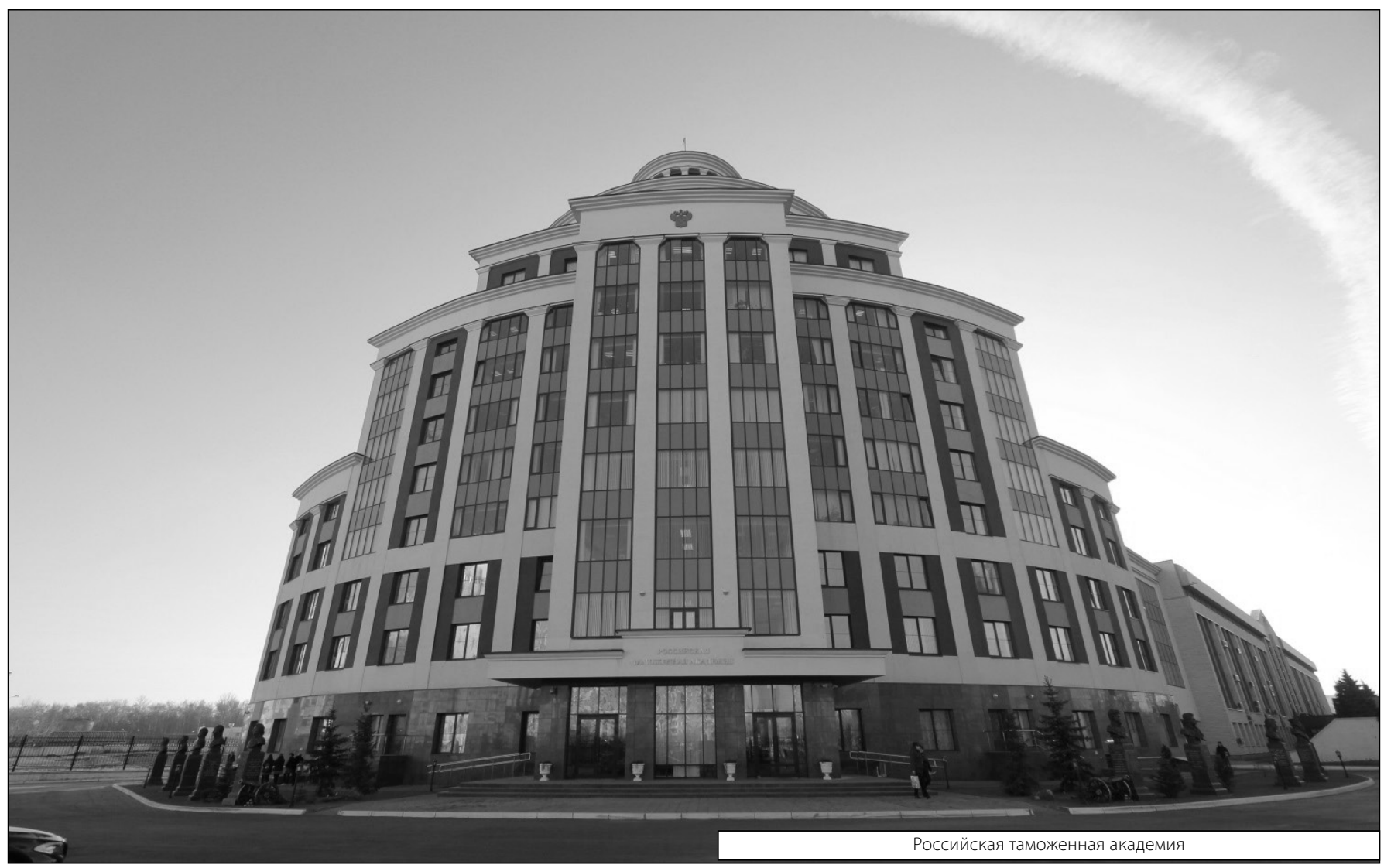

